\title{
SELF-ALIGNED 0-LEVEL SEALING OF MEMS DEVICES BY A TWO LAYER THIN FILM REFLOW PROCESS
}

\author{
Cristina Rusu ${ }^{1}$, Henri Jansen ${ }^{2}$, Robert Gunn ${ }^{3}$, Ann Witvrouw \\ IMEC, MCP/MS department, Kapeldreef 75, B-3001 Leuven, Belgium, witvrouw@imec.be \\ ${ }^{1}$ now with Imego Institute, MEMS group, Gothenburg, Sweden \\ ${ }^{2}$ University of Twente, Transducers Science and Technology Group, Enschede, The Netherlands \\ ${ }^{3}$ Surface Technology Systems plc, Newport, United Kingdom
}

\begin{abstract}
Many micro electromechanical systems (MEMS) require a vacuum or controlled atmosphere encapsulation in order to ensure either a good performance or an acceptable lifetime of operation. Two approaches for wafer-scale zero-level packaging exist. The most popular approach is based on wafer bonding. Alternatively, encapsulation can be done by the fabrication and sealing of perforated surface micromachined membranes.

In this paper, a sealing method is proposed for zerolevel packaging using a thin film reflow technique. This sealing method can be done at arbitrary ambient and pressure. Also, it is self-aligned and it can be used for sealing openings directly above the MEMS device. It thus allows for a smaller die area for the sealing ring reducing in this way the device dimensions and costs.

The sealing method has been demonstrated with reflowed aluminium, germanium, and boron phosphorous silica glass. This allows for conducting as well as nonconducting sealing layers and for a variety of allowable thermal budgets. The proposed technique is therefore very versatile.
\end{abstract}

\section{INTRODUCTION}

Unlike CMOS chips, chips containing MEMS devices cannot be directly packaged in a plastic or ceramic housing, the so-called first level package. MEMS structures have free-standing and/or moving parts that can easily be damaged during dicing or assembly. To prevent this damage, these structures should be protected on the wafer level, before dicing. This is possible with the socalled zero-level package. Besides protection against damage during assembly, this zero-level package can also be used to hermetically seal the MEMS device and/or to enclose it in a controllable atmosphere. This might be necessary to ensure a good operation and lifetime of the MEMS device.

Zero-level packaging is typically done by bonding a capping wafer or die to the MEMS wafer [1]. However, this increases the die area substantially and it needs alignment. Alternatively, hermetic encapsulation can be done by the fabrication and sealing of surface micromachined membranes covering the MEMS device by use of films deposited at low pressure, such as low pressure chemical vapour deposition (LPCVD) films [25]. However, atmospheric or near-atmospheric sealing is required for the operation of certain important MEMS devices, such as accelerometers.

Techniques at atmospheric pressure, other than capping, are often expected to have detrimental effects on the device. For example, although most atmospheric pressure CVD techniques (APCVD) have improved sealing capabilities with respect to LPCVD, too much material would deposit inside openings onto the MEMS' active parts. Moreover, with CVD or physical vapour deposition (PVD) techniques the gas composition surrounding the MEMS device cannot be altered at will. Alternatively, volume expansion and therefore sealing during thermal oxidation of e.g. silicon will close the sacrificial etch openings of a silicon membrane. This process is however usually done at temperatures exceeding $900^{\circ} \mathrm{C}$, which is too high for a lot of MEMS materials. Finally, the use of a tenting foil to seal the MEMS structure is limited due to outgassing in case a polymer foil is used. In case a metal foil is used for encapsulation, it is difficult to obtain a good adhesion of the film to the device wafer.

State-of-the-art sealing is in general done using horizontal sacrificial etch channels (fig.1). However, in order to have a high-speed sacrificial etching process underneath the surface micromachined membrane and in order to maintain a planar surface, sacrificial etch perforations in the membrane are favourably situated above the device (fig.2) [2]. Unfortunately, such vertical openings increase the risk of depositing sealing material on the device.

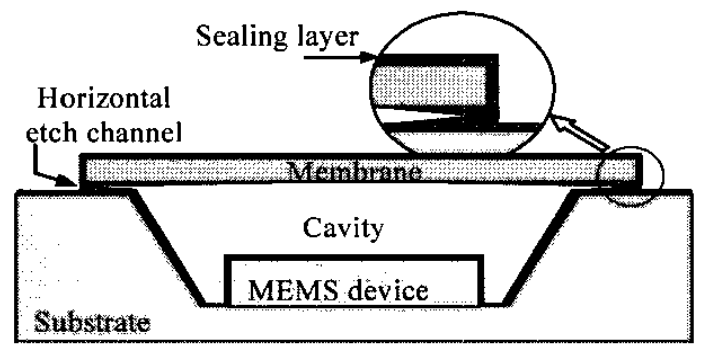

Figure 1. Schematic view of a microcavity with associated horizontal etch channel 


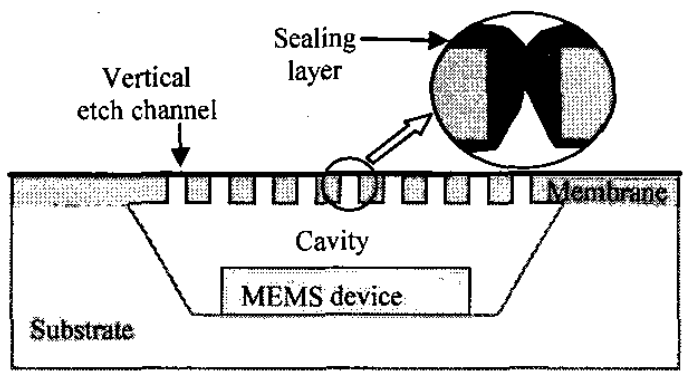

Figure 2. The use of a thin film to encapsulate a $M E M S$ device and a zoom in showing the vertical sealing concept.

With respect to the aforementioned remarks, the goal of this work is to find a sealing method for a MEMS device covered by a surface micromachined membrane fulfilling the following requirements:

- It leaves the device undamaged (low temperature, ...),

- It has the ability to control the pressure and gas composition inside the cavity. Vacuum, normal, and super-atmospheric pressures should be possible,

- It is durable and seals the device from the environment (humidity, dust, ...),

- It is a wafer-level sealing technique,

- It is a batch process,

- It leads to a reduced die area compared to standard packaging techniques,

- It is a cheap technique (reduce packaging price).

The sealing method for zero-level packaging that is proposed here uses a thin film reflow technique. This technique is self-aligned and seals the device from the environment. It allows a great flexibility with respect to the choice of the sealed-in gas and pressure and it offers compatibility with low-cost high-throughput batch fabrication techniques. Also, as it can be used for sealing openings directly above the device, it allows for a smaller die area and thus reduced device dimensions and costs.

The basic idea of the proposed technique is to deposit a material with low melting temperature on top of openings forming a cusp until they are almost closed (fig.3a). This material is then reflowed in a furnace with controlled atmosphere and pressure to close the final openings (fig.3b).
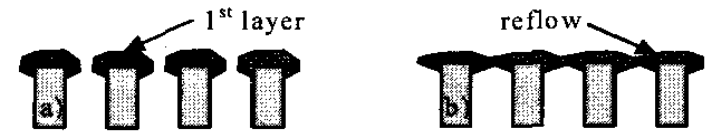

Figure 3. The one-layer sealing process: The use of low-temperature melting material to close an opening at arbitrary chosen pressure and ambient.
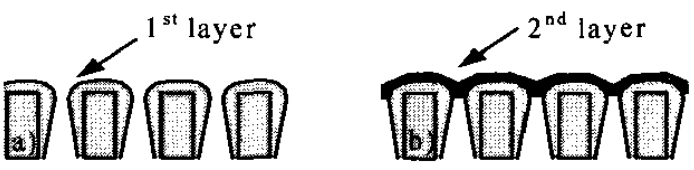

Figure 4. The two-layer sealing process: Sealing of a cavity with an additional intermediate layer to prevent reflow of the cusp and mixing of the membrane with the sealing material.

Obviously, a one-layer sealing process as shown in figure 3 has the risk that the film relaxes during reflow, thereby removing the cusp and opening the etch channels more instead of closing them. Therefore, a somewhat more complex sealing process is considered by adding an intermediate layer. The intermediate layer is stable during reflow and narrows down the opening to be sealed (fig. $4 \mathrm{a}$ and b). Moreover, the extra layer prevents reaction between the sealing and membrane layer.

\section{EXPERIMENT}

Initial tests with simple high aspect ratio trenches in silicon wafers have been performed to find optimum conditions to seal vertical trenches. These trenches resemble the perforated membrane covering a cavity with a MEMS device as shown in fig. 2.

Using these patterned silicon wafers, different materials are deposited at low pressure until the trench is nearly closed and finally this layer is reflowed at a chosen pressure and ambient to seal the trench (fig.3). Alternatively, a non-conformal intermediate layer has been deposited first followed by a second reflow layer to seal the cavity in the final reflow step (fig.4).

\subsection{Sample preparation}

Silicon wafers, $150 \mathrm{~mm}$ in diameter, with approximately $12 \mu \mathrm{m}$ deep trenches with widths varying between $1 \mu \mathrm{m}$ and $16 \mu \mathrm{m}$ were prepared by deep reactive ion etching (DRIE) using a resist mask.

\subsection{Deposition systems and parameters}

The materials investigated for the one-layer sealing process were germanium $(\mathrm{Ge})$, aluminium $(\mathrm{Al})$, and boron phosphorous silica glass (BPSG). In case of the two-layer sealing process, a non-conformal silicon dioxide $\left(\mathrm{SiO}_{2}\right)$ layer was deposited first. The thickness of the various deposited layers has been determined by optical spectral analysis for the silica glasses and by measuring the film step height using a surface profiler after film patterning by selective etching with respect to the underlayer for the other films. 


\subsubsection{LPCVD Ge and PECVD Ge}

The CVD depositions were done using an Oxford Plasma Technology (OPT) Plasma Lab 100 system, which is a PECVD/LPCVD cold wall system. It has a chuck enabling a maximum wafer temperature of $700^{\circ} \mathrm{C}$. For Ge thin film deposition, $10 \%$ germane $\left(\mathrm{GeH}_{4}\right)$ in hydrogen $\left(\mathrm{H}_{2}\right)$ has been used. All layers were deposited at a wafer temperature of $400^{\circ} \mathrm{C}$ and a pressure of 2 Torr. For PECVD depositions a power of $10 \mathrm{~W}, 20 \mathrm{~W}$ or $50 \mathrm{~W}$ has been used. For LPCVD Ge and PECVD Ge depositions at $10 \mathrm{~W}$ and $20 \mathrm{~W}$, an amorphous Si nucleation layer was first deposited at $60 \mathrm{~W}$ and 0.6 Torr in order to enhance nucleation of $\mathrm{Ge}$ on oxide.

\subsubsection{PVD Al}

The Al was evaporated using a Pfeiffer PLS 580 evaporator with a background pressure better than $10^{-6}$ mbar using a turbo pump vacuum system. The $\mathrm{Al}$ source material had a purity exceeding $99.999 \%$ and deposited at a rate of ca. $100 \mathrm{~nm} / \mathrm{min}$.

\subsection{3. $\mathrm{PECVD} \mathrm{SiO} \mathrm{S}_{2}$ intermediate layer for $\mathrm{Al}$ and $\mathrm{Ge}$}

The low tensile stress $\mathrm{SiO}_{2}$ layers were deposited from a gas mixture of silane $\left(\mathrm{SiH}_{4}\right)$, nitrous oxide $\left(\mathrm{N}_{2} \mathrm{O}\right)$, hydrogen $\left(\mathrm{H}_{2}\right)$ and nitrogen $\left(\mathrm{N}_{2}\right)$ using the same equipment as what was used for the PECVD Ge. All layers were deposited at $500^{\circ} \mathrm{C}, 100 \mathrm{~W}$ and 2 Torr. The films have $10 \mathrm{MPa}$ tensile stress, a 1.5 refractive index, and a deposition rate of $225 \mathrm{~nm} / \mathrm{min}$.

\subsection{4. $P E C V D \mathrm{SiO}_{2}$ intermediate layer for BPSG and PECVD BPSG}

Depositions were carried out in a Multiplex PECVD system using a gas mixture of silane $\left(\mathrm{SiH}_{4}\right)$, nitrous oxide $\left(\mathrm{N}_{2} \mathrm{O}\right)$, hydrogen $\left(\mathrm{H}_{2}\right)$ and nitrogen $\left(\mathrm{N}_{2}\right)$. The PECVD $\mathrm{SiO}_{2}$ layers were deposited at low pressure with a 1.47 refractive index at $450 \mathrm{~nm} / \mathrm{min}$. Diborane in hydrogen and phosphorous in argon were used as the dopants for the PECVD BPSG films to give a deposition rate of 900 $\mathrm{nm} / \mathrm{min}$ and a refractive index of 1.48 .

\subsection{Reflow systems}

The reflow of $\mathrm{Al}$ and $\mathrm{Ge}$ was performed in a Rapid Thermal Process (RTP) furnace in a $\mathrm{N}_{2}$ atmosphere. For some experiments also a commercial available furnace was used. The reflow of BPSG was carried out in a commercial available tube furnace at $1100^{\circ} \mathrm{C}$ for $1 \mathrm{hr}$.

\section{RESULTS and DISCUSSION}

\subsection{One-layer sealing process}

For our application we are interested to close 2-3 $\mu \mathrm{m}$ wide trenches by reflow. Trenches of this large width are needed to have a reasonable etch time of the sacrificial layer underneath the membrane (fig.2).

\subsubsection{Reflow with PECVD BPSG}

The initial idea was to see if depositing a single layer of BPSG could be used as a sealing layer. The BPSG film has reasonable step coverage but like all PECVD films more material is deposited on the top surface of the structure compared to the sidewall as shown in fig.4a. This leads to a cusp being formed at the corner of the trench opening. The BPSG films were deposited until the cusps were almost touching and the films were then reflowed. Unfortunately the films just relaxed and did not seal.

\subsubsection{Reflow with evaporated Al}

The easiest metal to use as reflow material is Al because it has a low melting point and it can also be used as an electrical contact layer besides sealing the trenches. We deposited up to $3 \mu \mathrm{m} \mathrm{Al}$ on Si trenches and after 3 hours in an oven or RTP furnace with flowing nitrogen at $550^{\circ} \mathrm{C}, \mathrm{Al}$ didn't reflow. Possibly an oxide layer, which is formed on top of $\mathrm{Al}$ during the heating and which has a much higher melting temperature than $\mathrm{Al}$ itself, prevents this reflow. Moreover, at a temperature above $450^{\circ} \mathrm{C}$, spiking with the Si was observed. An intermediate layer between $\mathrm{Si}$ and $\mathrm{Al}$ is thus needed in order to avoid this reaction.

\subsubsection{Reflow with LPCVD Ge and PECVD Ge}

The maximum trench width that can be closed off with a single layer of LPCVD and PECVD Ge was investigated. An LPCVD film has conformal step coverage and can fill trenches with a width equal to twice the deposited thickness [6]. Therefore, it will not be used further as too much material gets inside the trenches.

Just like the PECVD BPSG, PECVD Ge closes trenches from the top with poor step coverage and with little material in the trench [6]. Lowering the PECVD power, and therefore approaching LPCVD conditions, increases the step coverage and thus also the unwanted bottom coverage. Therefore, PECVD Ge at sufficient PECVD power was tried for reflow. $2 \mu \mathrm{m} \mathrm{Ge}$ was deposited at 20 Watt on Si trenches and different reflow conditions were tried. Anneals in an RTP furnace with flowing nitrogen for $1 \mathrm{hr}$ at $750^{\circ} \mathrm{C}$ and for $2 \mathrm{hr}$ at $700^{\circ} \mathrm{C}$ were tried. However, just like the PECVD BPSG, it was not possible to close the trenches by reflow that were open before reflow. 


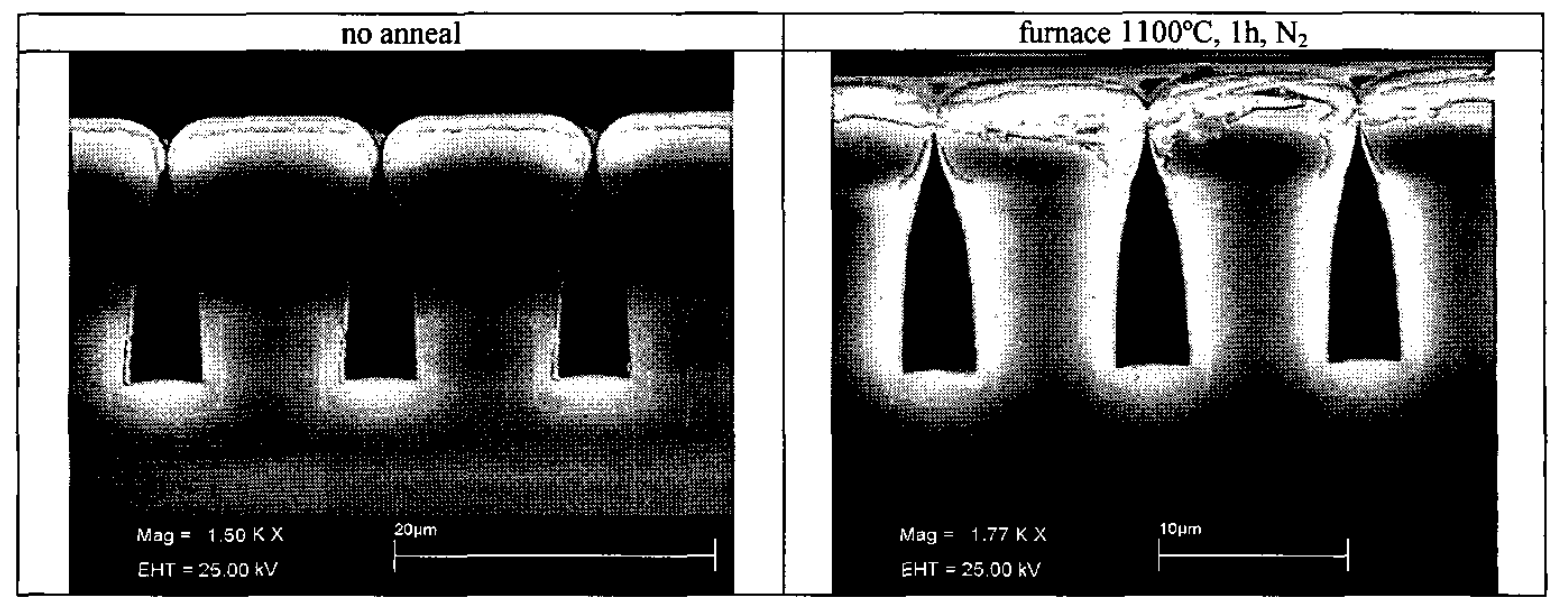

Figure 6. $0.5 \mu \mathrm{m}$ deposited BPSG on $9 \mu \mathrm{m}$ PECVD SiO ${ }_{2}$ on Si trenches (6 im deep) before and after reflow.

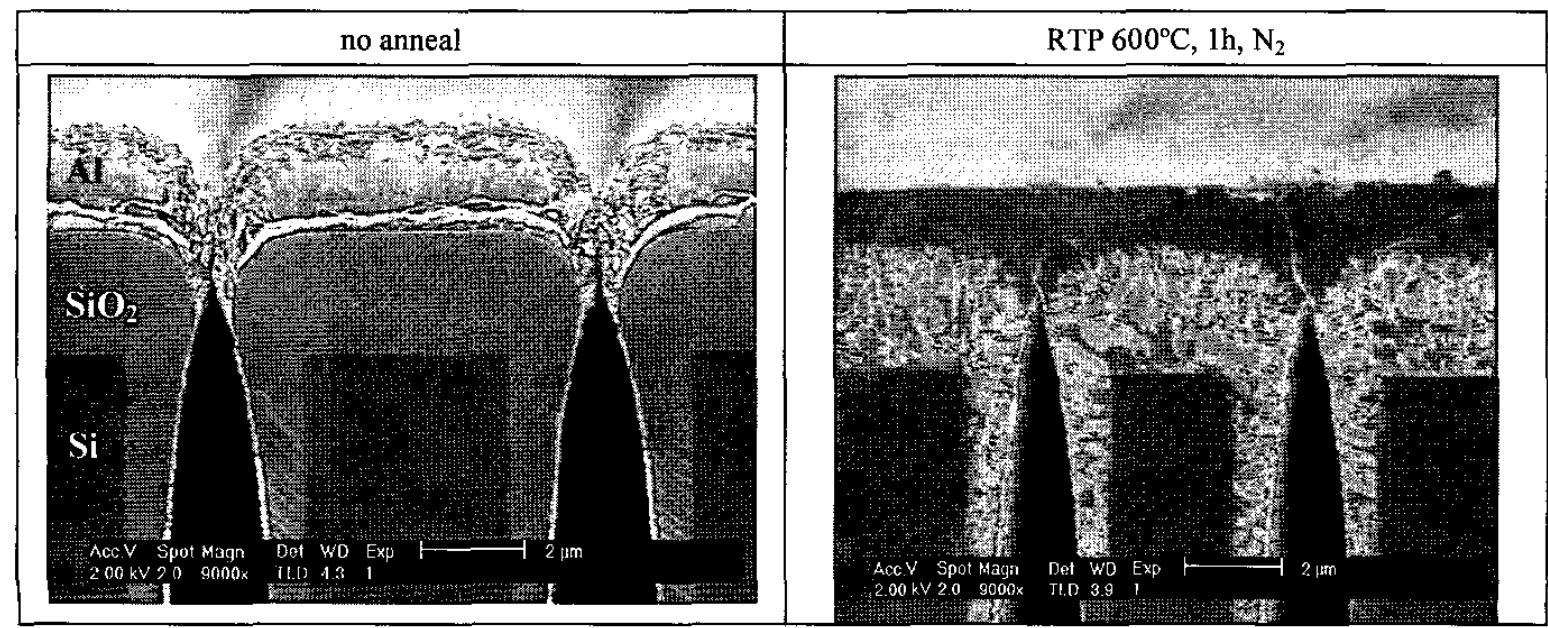

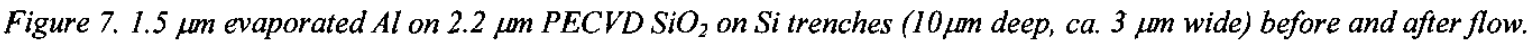

\subsection{Two-layers sealing process}

As presented in the previous section, reflow with one layer did not satisfy the sealing requirements, mainly due to film relaxation and reaction of the thin film with the membrane material. Therefore, the use of an intermediate layer was investigated. This layer should not relax during reflow and should prevent reactions with the $\mathrm{Si}$ membrane. PECVD $\mathrm{SiO}_{2}$ has been chosen because of its poor step coverage and sufficient high melting temperature.

\subsubsection{Reflow with BPSG}

On top of the intermediate PECVD $\mathrm{SiO}_{2}$ layer, BPSG glass is deposited, which, depending on its $\mathrm{B}$ and $\mathrm{P}$ content, will readily flow to seal trenches. As can be seen in fig. 6 , before the reflow of the BPSG the trenches are open and after the reflow treatment they are sealed. The trench widths used for the experiment were $6 \mu \mathrm{m}$, but with a little adjustment to the parameters smaller or larger trenches could easily be sealed.

\subsubsection{Reflow with Evaporated Al}

Also here $\mathrm{PECVD} \mathrm{SiO}_{2}$ is chosen as an intermediate layer on top of which $1.5 \mu \mathrm{m}$ of aluminium is evaporated. The layer was reflowed under the same conditions as in 3.1.2 $\left(550^{\circ} \mathrm{C}\right.$ for lhour in a $\mathrm{N}_{2}$ atmosphere), but no reflow was observed. After increasing the anneal temperature to $600^{\circ} \mathrm{C}$, while keeping the other annealing conditions the same, the Al reflowed, closing the trenches as can be seen in fig. 7 . 


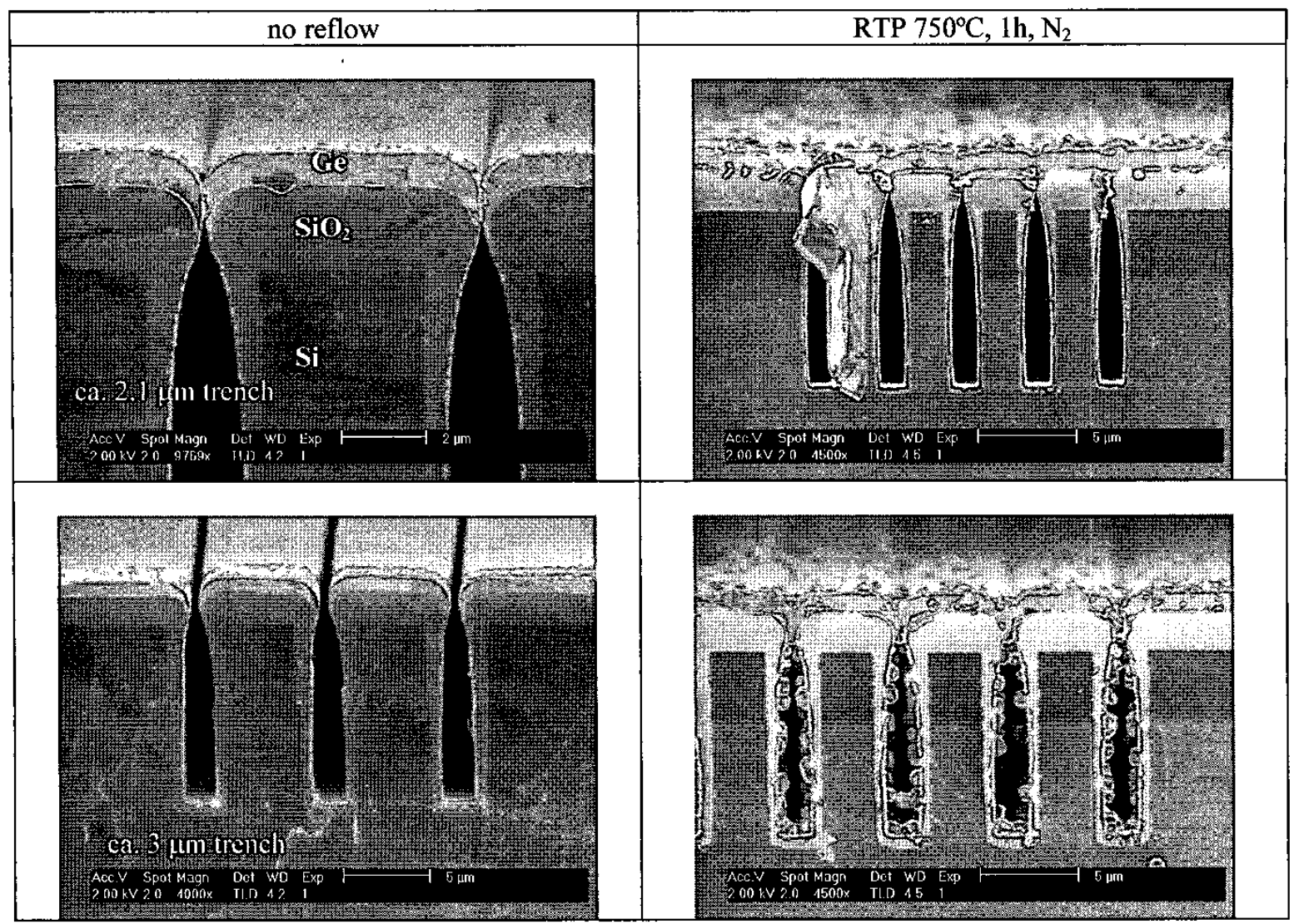

Figure 8. $1 \mu \mathrm{m}$ PECVD Ge, $50 \mathrm{~W}$, on $2.2 \mu \mathrm{m} \mathrm{PECVD} \mathrm{SiO}{ }_{2}$ on Si trenches (10 $\mu \mathrm{m}$ deep) before and after reflow.

\subsubsection{Reflow with PECVD Ge}

The RF power for the PECVD Ge was varied between 20 $\mathrm{W}$ and $50 \mathrm{~W}$. The higher the power, the worse the step coverage. Different $\mathrm{Ge}$ thickness and annealing conditions were tried such that before annealing, the $2 \mu \mathrm{m}$ wide trenches were almost closed by $\mathrm{Ge}$ and the $3 \mu \mathrm{m}$ wide trenches were left open. Both trenches have to be closed after reflow. The film surface of Ge deposited at $20 \mathrm{~W}$ is much rougher (before and after annealing) than that deposited at $50 \mathrm{~W}$. The most promising film is $\mathrm{Ge}$ deposited at $50 \mathrm{~W}$ and reflowed at $750^{\circ} \mathrm{C}$ for 1 hours (fig. 8). The debris, which can be seen inside some of the trenches, may be Ge that reflowed inside the trench before the trench was fully closed. Some $\mathrm{SiO}_{2}$ can be seen on the bottom of the trenches but this thin layer (ca. 100-200nm) is expected not to be harmful for the MEMS device.

\subsection{Variation on the two-layers sealing process}

The two-layer sealing process described above is intended to be used to seal etch holes of equal width. A variation on this technique is however a two-layer sealing process which uses an additional 'vent' hole. This vent hole is introduced away from sensitive device areas, and has a diameter larger than the trenches in the membrane (see for example fig. 9). The first layer from which not too much material is deposited into the sensitive device areas could then seal the trenches. The vent hole could then be sealed using a process, which could deposit material in the hole, but, as it is located away from the sensitive device areas, would not cause any harm to the device. This second layer could be a layer that is reflowed as mentioned above. But also a film that seals during the deposition process (e.g. an APCVD film if an atmospheric pressure inside the cavity is needed) might work for this concept because of the position of the vent hole. 


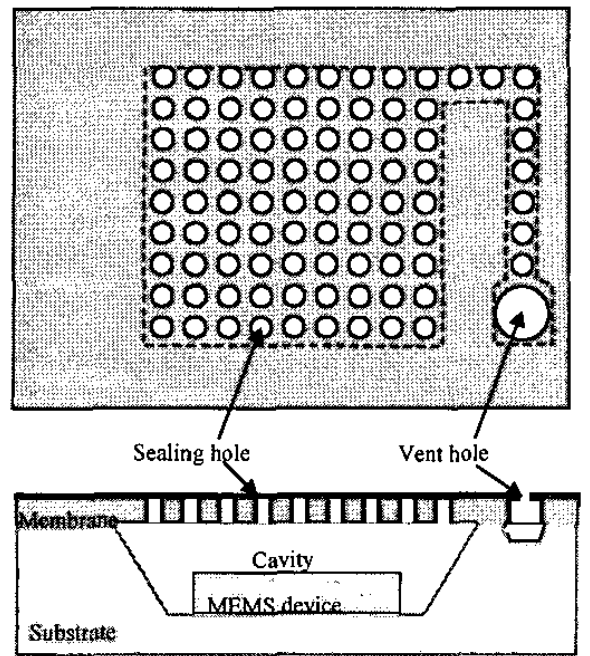

Figure 9. Schematic view of a microcavitv and a vent

\section{CONCLUSIONS}

Reflow of Ge, Al and BPSG have been used successfully to seal trenches with widths up to $6 \mu \mathrm{m}$. These materials were chosen both for ease of deposition and for their low melting points. The sealed-in pressure and atmosphere can be controlled and a $\mathrm{N}_{2}$ ambient at atmospheric pressure has been used for the experiments.

Experimentally it was found that this method works best in combination with an intermediate layer, which prevents reaction between sealing and membrane layer, is stable during reflow and narrows down the opening to be sealed. An intermediate layer that gave good results for the three sealing materials tested was PECVD Si-oxide. This Si-oxide layer can act as an electrically insulating layer in between the membrane layer and the sealing layer.

This sealing process is expected to provide an hermetic seal, the sealing layer material can be chosen such that the reflow temperature is compatible with the MEMS device to be packaged and the reflow layer, such as in the case of an $\mathrm{Al}$ reflow layer, can act as an interconnection layer of the device. The two layers of the process can thus be used as functional layers and the resulting surface is planar, allowing further processing.

\section{ACKNOWLEDGEMENTS}

The authors would like to thank Sherif Sedky for deposition of LPCVD Ge and some PECVD Ge. The authors would also like to thank to Silvia Kronmueller from Robert Bosch $\mathrm{GmbH}$, Germany for fruitful discussions. This work is partly financed by the IST project SUMICAP (IST-1999-10620) of the European Commission

\section{REFERENCES}

[1] H.A.C. Tilmans, M.D.J. Van de Peer, E. Beyne, "The intend reflow sealing (IRS) technique-a method for fabrication of sealed cavities for MEMS devices", J.MEMS, 9, p.206-217, 2000.

[2] A. Partridge, A.E. Rice, T.W. Kenny, M. Lutz, "New thin film epitaxial polysilicon encapsulation for piezoresistive accelerometers", Proc. MEMS 2001, p.54-59, 2001.

[3] C. Rusu, A. Verbist, B. Parmentier, A. Witvrouw, "MEMS 0 -level packaging using thin-film poly-SiGe caps", Proc. MEMS workshop of International Microelectronics and packaging Society (IMAPS), Sept 6-8, 2002, Denver, USA.

[4] R. Legtenberg, H.A.C. Tilmans, "Electrostatically driven vacuum encapsulated polysilicon resonators, Part I: Design and fabrication", Sensors and Actuators A 45, p. 57-66, 1994.

[5] C. Liu, Y.C. Tai, "Sealing of micromachined cavities using chemical vapor deposition methods: characterisation and optimization", J.MEMS, 8, p.135-145, 1999.

[6] C. Rusu, G. Klaasse, S. Sedky, H. Esch, B. Parmentier, A. Verbist, A. Witvrouw, "Planarization of deep trenches", Proc. SPIE Micromachining and Microfabrication Process technology VII, 22-24 Oct. 2001, San Francisco, CA, USA, p 49-57, 2001. 